\title{
Screening of Diabetic Retinopathy in Patients with Type 2 Diabetes in a Community of the Paraíba Semi-Arid Using Original Score
}

\author{
Milena Souza Amorim¹, Sebastião Cronemberger Sobrinho², \\ Maria Cecília Santos Melo Cavalcanti', Ana Luiza Motta', Diego Nery Benevides Gadelha', \\ Carlos Teixeira Brandt ${ }^{1}$ \\ ${ }^{1}$ Medical School, Campina Grande, Paraíba, Brazil \\ ${ }^{2}$ Full Professor of Ophthalmology, Federal University of Minas Gerais, Belo Horizonte, Brazil \\ Email: carlosbrandt@bol.com.br
}

How to cite this paper: Amorim, M.S., Sobrinho, S.C., Cavalcanti, M.C.S.M., Motta, A.L., Gadelha, D.N.B. and Brandt, C.T. (2021) Screening of Diabetic Retinopathy in Patients with Type 2 Diabetes in a Community of the Paraíba Semi-Arid Using Original Score. Open Journal of Ophthalmology, 11, 1-17.

https://doi.org/10.4236/ojoph.2021.111001

Received: November 10, 2020

Accepted: January 26, 2021

Published: January 29, 2021

Copyright $\odot 2021$ by author(s) and Scientific Research Publishing Inc. This work is licensed under the Creative Commons Attribution International License (CC BY 4.0)

http://creativecommons.org/licenses/by/4.0/

\begin{abstract}
Introduction: Diabetic retinopathy (DR) is neglected in the planning of health services in Brazil. The purpose of this study was to investigate the frequency of Diabetic Retinopathy in patients with type 2 diabetes mellitus (DM2) registered in the Unified Health System (SUS) of the semi-arid of Paraíba (PB-Brazil), using a score developed by the researchers to track this condition. Methods: A cross-sectional study was carried out, in which DM2 patients registered at SUS in the city of São Mamede-PB was recruited. Ophthalmological and clinical data were collected, including: body mass index (BMI), waist circumference (WC), waist circumference/height ratio (WC/stature), smoking history, physical activity, time of diabetes and its control, blood pressure values and comorbidities. With these data, an original score for DR screening (DRSS) was performed. Qualitative variables were expressed by absolute and relative frequencies, and quantitative variables were expressed by means and standard deviations. $p$ value $\leq 0.05$ was used to reject the null hypothesis. Results: Ninety seven (64.7\%) type 2 diabetic patients were recruited. Participants were predominantly women (64.9\%), with a mean age of 65.8 years, of short stature (mean of $1.56 \mathrm{~m}$ ), high BMI, with a predominance of the $\mathrm{WC} /$ stature ratio equal to or greater than 0.60 , smokers and patients with systemic arterial hypertension (SAH). The main ophthalmological findings were: vascular changes compatible with Grade I/II Hypertensive Retinopathy (72.1\%) and cataracts in about $50 \%$ of the eyes. The prevalence of DR was $12.4 \%$. According to the DRSS results, it was found that most patients $(85.6 \%)$ had a high risk score equal to or greater than 60 of developing DR. It was observed that the variables: WC, physical activity, time of
\end{abstract}


diabetes and SAH showed a significant association with the risk of developing DR. In addition, BMI and WC/height ratio with higher values had a high risk of developing DR. Conclusion: There was association between medium and high DRSS risk diabetics with the probability of developing DR, recommending that all people with these characteristics should be referred to the specialist in order to screen for DR and other morbidities caused by diabetes.

\section{Keywords}

Diabetes Mellitus Type II, Diabetic Retinopathy, Semi-Arid from Paraíba, Disease, Risk Factors

\section{Introduction}

Type 2 diabetes mellitus (DM2) attracts great attention worldwide due to its increasing incidence and multiple associated complications. It became epidemic in the 21 st century, in which about 451 million adults worldwide are affected and, by 2040, that number will reach 642 million (10\% of adults). Consequently, the incidence of ocular complications secondary to diabetes is expected to increase substantially, mainly due to the limited knowledge of the signs and symptoms of this condition by patients [1]-[8].

Diabetic retinopathy $(\mathrm{RD})$ has an insidious onset and can lead to blindness in $75 \%$ of diabetic patients with more than 20 years of disease [9]. Its prevalence as a disease that threatens vision and produces blindness is variable worldwide with a confidence interval between 3 and $8 \%$ of patients with diabetes [10] [11].

Despite its importance, DR has been neglected in the planning of health services in Brazil, where access to ophthalmologists and tertiary eye care services is inadequate [12] [13], therefore there is a lack of systematic screening for RD [14], especially in the northeastern region of this country.

In developed countries, such as England, the three-year screening interval has been safely adopted for patients with DM2 without retinopathy, while annual or more frequent screening is performed for those with more severe degrees of retinopathy. In Brazil, the frequency of DR screening with risk of impaired vision is few, hence the justification for this research, since the knowledge of data on the main causes of visual impairment and blindness form an important basis for recommendations of public health policies. In addition, the cost-benefit ratio of systematic screening for DR in DM2 patients has been considered positive in developed countries [15] [16] [17] [18].

In non-developed countries, systematic screening programs for the entire population are expensive [19]. The Indian Diabetes Risk Score (IDRS), a simple screening tool for predicting undiagnosed diabetes, developed at the Madras Diabetes Research Foundation (MDRF), Chennai, India was very effective [20], raising the question why not create a Diabetic Retinopathy Screening Score (DRSS), which could be used by general physician operating in Basic Health Units in 
Brazil, in order to more efficiently rationalize scarce resources, especially in the countryside that hardly has access to specialized services, such as ophthalmology. Therefore, the purpose of this study was to investigate the frequency of Diabetic Retinopathy in patients with DM2 registered in the National Health System (SUS) in the semi-arid region of Paraíba, using the original score developed by the study researchers.

\section{Methods}

An observational, cross-sectional and analytical study was performed in the city of São Mamede, in the semi-arid region of Paraíba (Northeastern region of Brazil), with a population of 7721 (seven thousand seven hundred and twenty-one) inhabitants. The study, performed from May to November 2019, included type II diabetic patients registered at Unified Health System-Brazil (SUS) in the city of São Mamede with ages ranging from 45 to 70 years. Type 1 diabetic patient and those who had previously eaten before 6 hours required to measure glycemic levels (HGT), as well as patients with eye opacity, in which the retina could not be examined were excluded.

Clinical and ophthalmological examinations were performed on humanitarian mission systems. For this, an ophthalmological mobile unit from the UNIFACISA University Center was used. DM2 patients were screened at the Basic Health Units by community health agents in partnership with the Municipal Health Department. Initially, they were interviewed regarding age, anthropometric data (weight, height, body mass index-BMI, waist circumference-WC and waist circumference/height ratio), social habits (smoking), physical activity (sedentary or non-existent physical activity, light level—housework, moderate level—walking and intense level-regular physical activity at the gym), time of diabetes, fasting blood glucose (using HGT), systemic blood pressure levels and comorbidities. For all patients included in the study, the results of the diabetic retinopathy screening score (DRSS-Figure 1-attachment) were completed, a score developed by the research team according to data found in the literature. Points were assigned to each of these variables, whereas DM2 patients with a score equal to or greater than 60 were considered to be at high risk for the development of DR, therefore, its quick referral to cardiologist, ophthalmologist, nephrologist and breast specialist is necessary. Patients with a score between 30 and 59 were considered to be of medium risk and would only need an annual reassessment, and patients with a score below 30 were considered to be at low risk for the development of DR.

After the clinical evaluation, the patients were referred for a complete eye examination, which included: Visual Acuity Exam from Far (5 meters) and up close (33 centimeters) using the Snelling and Jaeger chart, respectively. Subsequently, the bio microscopy exam of the anterior segment was performed, using the digital slit lamp SL-D701 from the company Topcon Europe Medical. Then, tonometry was performed using the OPTILAZA Lux Vision-Oftech applanation tonometer and, finally, the retinal mapping exam, under drug mydriasis, 
Name:

Age

\begin{tabular}{|c|c|}
\hline Diabetic Retinopathy Screening Score (DRSS) & \\
\hline Risk factor category & Score \\
\hline \multicolumn{2}{|l|}{ Age } \\
\hline - Less than 40 years & 0 \\
\hline - $\quad$ Between 40 e 59 anos & 5 \\
\hline - Equal or greater than 60 yars & 10 \\
\hline \multicolumn{2}{|l|}{ Abdominal obesity } \\
\hline - Woman or man waist circumference less than $80 \mathrm{~cm}$ & 0 \\
\hline - Woman or man waist circumference between 80 and $89 \mathrm{~cm}$ & 10 \\
\hline - Woman or man abdominal circumference equal to or greater than $90 \mathrm{~cm}$ & 20 \\
\hline \multicolumn{2}{|l|}{ BMI equal to or greater than 35} \\
\hline Physical activity & 10 \\
\hline - Intensive activity or intense activity at work & 0 \\
\hline - Moderate exercise or at home & 5 \\
\hline - Light exercise at work or at home & 15 \\
\hline - No exercise at home or at work & 20 \\
\hline \multicolumn{2}{|l|}{ History of diabetes } \\
\hline - $\quad$ Being diabetic for less than 10 years, controlled (HbA1c <6.4\%) & 5 \\
\hline - Being diabetic for less than 10 years, out of control (HbA1c>6.4\%) & 10 \\
\hline - $\quad$ Being diabetic for more than 10 years, controlled ( $\mathrm{HbAlc}<6.4 \%)$ & 15 \\
\hline - Being diabetic for more than 10 years, out of control (HbA1c>6.4\%) & 20 \\
\hline \multicolumn{2}{|l|}{ Diabetes Time } \\
\hline - Being diabetic for less than 10 years & 5 \\
\hline - Being diabetic for more than 10 years & 10 \\
\hline Being a smoker, ex-smoker or passive smoker Height:_ & 10 \\
\hline Systolic blood pressure_____ Diastolic ___ & Escore total \\
\hline Hypertension Controlled hypertension & \\
\hline
\end{tabular}

Conduct: Score equal to or greater than $60=$ high risk; Refer to the cardiologist, ophthalmologist, nephrologist and mastologist; Score between 30 and 59 = medium risk; Annual revaluation; Score less than $30=$ low risk.

Figure 1. (Attachment) Clinical questionnaire.

with the aid of Eyetec's Indirect Binocular Ophthalmoscope. All data were recorded in medical records and all participants were examined by the same professionals.

The data provided by the score and medical records were fed into Excel spreadsheets and analyzed statistically using the GraphPad program.

The patient representative city sample was at random. Qualitative variables were expressed by absolute and relative frequencies, whereas quantitative variables were expressed by means, medians and dispersion values. The chi-square tests, Fisher's exact test and Fisher-Freeman-Halton test were used to verify the existence of an association between qualitative variables. The Student " $t$ " test was used to verify differences between means, when the numerical sets had passed the normality test. For numerical sets that did not pass the normality test, the difference between means was calculated using the Mann-Whitney test. A p-value equal to or less than 0.05 was used to reject the null hypothesis.

The project was approved by the Research Ethics Committee of the Faculty of Medical Sciences of Campina Grande/UNIFACISA ruled by the National Commission for Research Ethics. The recruited individuals included in the research signed a free and informed consent form.

\section{Results}

Ninety seven (64.7\%) type 2 diabetic patients registered in the database of the 
health department of the city of São Mamede-Paraíba were included in the study.

Demographic data (gender, age, body mass index, physical activity and daily living habits) are described in Table 1.

Patients had a mean fasting blood glucose level of $183 \pm 77 \mathrm{mg} / \mathrm{dl}$. The mean systolic blood pressure was $152 \pm 20 \mathrm{mmHg}$ and the diastolic blood pressure was $89 \pm 15 \mathrm{mmHg}$.

Most patients, 62 (63.9\%) were diagnosed with Diabetes Mellitus (DM) less than 10 years ago, of these, half had DM under control. It was also found that $94.8 \%$ of patients had arterial hypertension, of these, 56 (57.7\%) had uncontrolled disease (Table 2).

Table 1. Demographic and habit patient parameters.

\begin{tabular}{|c|c|c|c|c|c|}
\hline \multicolumn{2}{|c|}{ Control Variables } & \multirow{2}{*}{$\begin{array}{l}\mathrm{n} \\
34\end{array}$} & \multirow{2}{*}{$\begin{array}{c}\% \\
35.1 \%\end{array}$} & \multirow[t]{2}{*}{ Mean } & \multirow[t]{2}{*}{ Standard Deviation } \\
\hline & Male & & & & \\
\hline Gender & Female & 63 & $64.9 \%$ & & \\
\hline \multicolumn{2}{|c|}{ Age (year) } & & & 65.8 & 10.6 \\
\hline \multicolumn{2}{|c|}{ Weight (kg) } & & & 70.4 & 14.4 \\
\hline \multicolumn{2}{|c|}{ Height (m) } & & & 1.56 & 0.1 \\
\hline \multicolumn{2}{|c|}{ BMI } & & & 29.3 & 4.3 \\
\hline \multicolumn{2}{|c|}{ WC/height ratio } & & & 0.63 & 0.06 \\
\hline \multirow{4}{*}{$\begin{array}{c}\text { Physical } \\
\text { activity }\end{array}$} & Intense & 2 & 2.1 & & \\
\hline & Moderate & 12 & 12.4 & & \\
\hline & Light & 47 & 48.5 & & \\
\hline & Sedentary & 36 & 37.1 & & \\
\hline \multirow{2}{*}{ Smoking } & Non-smoking & 26 & 26.8 & & \\
\hline & Smoker & 71 & 73.2 & & \\
\hline
\end{tabular}

Table 2. Clinical characteristics of DM evolution and comorbidities.

\begin{tabular}{cccc}
\hline \multicolumn{2}{c}{ Clinical Variables } & $\begin{array}{c}\text { Absolute frequency } \\
\mathrm{n}\end{array}$ & $\begin{array}{c}\text { Relative frequency } \\
\%\end{array}$ \\
\hline \multirow{2}{*}{ DM time } & More than 10 years & 35 & 36.1 \\
& Less than 10 years & 62 & 63.9 \\
DM control & Uncontrolled & 12 & 34.3 \\
(over 10 years) & Controled & 23 & 65.7 \\
DM control & Uncontrolled & 31 & 50.0 \\
(less than 10 years) & Controled & 31 & 50.0 \\
Systemic Arterial & Uncontrolled & 56 & 57.7 \\
Hypertension & Controled & 36 & 37.1 \\
& Absence of hypertension & 5 & 5.2 \\
\hline
\end{tabular}


It was observed that the visual acuity (AV) of the right eye (RE) varied between 0.0 and $1.6 \log$ MAR, with a mean of $0.32 \pm$ Standard Error of the Mean (SEM) of 0.05 , median of 0.00 . The left eye AV (LE) ranged from 0.0 to 1.6 $\operatorname{logMAR}$, with a mean of $0.34 \pm$ SEM of 0.05 , median of 0.00 . There was no statistically significant difference between the means of VA of the RE when compared to the LE $(\mathrm{p}=0.2459)$.

It was observed that 48 right eyes (49.4\%) had cataract, of these seven (14.6\%) had associated pterygium. Forty nine left eyes (50.5\%) had cataracts on examination of the anterior segment, of these eight (16.3\%) had associated pterygium. The main type of cataract was nuclear cataract, with $41 / 48$ (85.4\%) in RE and $41 / 49$ (83.7\%) in LE.

Regarding the RE, a pale optic nerve was observed in five (5.1\%) eyes; one eye (1.0\%) had optic nerve melanocytoma and one eye $(1.0 \%)$ had shunts on the optic disc. In the LE, three (3.1\%) patients with pale optic nerve were observed. The increased papillary excavation was found in eight (8.2\%) RE and nine $(9.3 \%)$ in LE.

A total of $70 / 97(72.1 \%)$ of the right and left eyes showed vascular changes compatible with the diagnosis of hypertensive retinopathy grade I-II, according to the Keith-Wagener-Barker classification, in addition to presence of signs of venous occlusion in one (1.0\%) right eye and one (1.0\%) left eye.

Macula with erase of the fovea reflex was found in 47/97 (48.4\%) RE and 45/97 (46.4\%) LE. It was also observed, four RE with clinically significant macular edema (4.1\%) and five LE with clinically significant macular edema (5.1\%), in addition to three RE and five LE with druse in the macula, respectively $3.1 \%$ and $5.1 \%$.

The intraocular pressure (IOP) of the RE ranged from 8 to $24 \mathrm{mmHg}$, with a mean of $13.3 \pm 3.2 \mathrm{mmHg}$ and a median of $13.0 \mathrm{mmHg}$. The IOP do LE ranged from 8 to $23 \mathrm{mmHg}$ and a mean of $13.4 \pm 3.3 \mathrm{mmHg}$ and a median of 13.0. There was no statistically significant difference between the means of the IOP of the RE when compared to the LE (Mann-Whitney test $-\mathrm{p}=0.8272$ ).

Eighty five participants $(87.6 \%)$ did not show signs of diabetic retinopathy, while seven $(7.2 \%)$ showed changes compatible with non-proliferative diabetic retinopathy (NPDR), five (5.1\%) with proliferative diabetic retinopathy (PDR).

According to the result of the diabetic retinopathy screening score (DRSS), it was found that 83 interviewed patients $(85.6 \%)$ presented with a high risk of developing DR (Table 3 ).

It was also found that the variables waist circumference, physical activity, time of diabetes and hypertension were associated with the risk of developing diabetic retinopathy (DRSS) (Table 4 ).

It was also found that $\mathrm{BMI}$ and $\mathrm{WC} /$ height ratio showed different means when compared to the medium and high risk of $\mathrm{DR}$, at the level of $\mathrm{p} \leq 0.05$. And that BMI and WC/height ratio with higher values had a high risk of developing DR. The other variables showed no difference between the DRSS (Table 5). 
Table 3. Risk of developing diabetic retinopathy according to the DRSS score.

\begin{tabular}{|c|c|c|c|}
\hline \multicolumn{2}{|c|}{ Variables } & Absolute frequency & Relative frequency \\
\hline \multirow{3}{*}{$\begin{array}{l}\text { DR risk } \\
\text { (DRSS) }\end{array}$} & High & 83 & 85.6 \\
\hline & Medium & 14 & 14.4 \\
\hline & Low & 0 & 0.0 \\
\hline
\end{tabular}

Table 4. Demographic data, anthropometric data, lifestyle, morbidity and evolution of DM by DRSS.

\begin{tabular}{|c|c|c|c|c|c|}
\hline \multirow{2}{*}{\multicolumn{2}{|c|}{ Variables }} & \multicolumn{2}{|c|}{ DRSS } & \multirow{2}{*}{ Total } & \multirow{2}{*}{ p-value } \\
\hline & & Medium risk & High risk & & \\
\hline \multirow{2}{*}{ Gender } & Male & $5(31.2 \%)$ & $29(35.8 \%)$ & $34(35.1 \%)$ & \multirow{2}{*}{$0.727^{\star}$} \\
\hline & Female & $11(68.8 \%)$ & $52(64.2 \%)$ & $64(64.9 \%)$ & \\
\hline \multirow{3}{*}{$\begin{array}{c}\text { Waist } \\
\text { circumference }\end{array}$} & $<80 \mathrm{~cm}$ & $1(6.2 \%)$ & $0(0.0 \%)$ & $1(1.0 \%)$ & \multirow{3}{*}{$0.001^{* * *}$} \\
\hline & $80-89 \mathrm{~cm}$ & $6(37.5 \%)$ & $3(3.7 \%)$ & $9(9.3 \%)$ & \\
\hline & $\geq 90 \mathrm{~cm}$ & $9(56.2 \%)$ & $78(96.3 \%)$ & $87(89.7 \%)$ & \\
\hline \multirow{4}{*}{$\begin{array}{l}\text { Physical } \\
\text { activity }\end{array}$} & Sedentary lifestyle & $1(6.2 \%)$ & $35(43.2 \%)$ & $36(37.1 \%)$ & \multirow{4}{*}{$0.001^{* * *}$} \\
\hline & Light & $6(37.5 \%)$ & $41(50.6 \%)$ & 47 (48.5\%) & \\
\hline & Moderate & $8(50.0 \%)$ & $4(4.9 \%)$ & $12(12.4 \%)$ & \\
\hline & Intense & $1(6.2 \%)$ & $1(1.2 \%)$ & $2(2.1 \%)$ & \\
\hline \multirow{2}{*}{ DM control } & Yes & $12(75.0 \%)$ & $42(51.9 \%)$ & $54(55.7 \%)$ & \multirow{2}{*}{$0.105^{* *}$} \\
\hline & No & $4(25.0 \%)$ & $39(48.1 \%)$ & $43(44.3 \%)$ & \\
\hline \multirow{2}{*}{ DM time } & Less than 10 years & $16(100.0 \%)$ & $46(56.8 \%)$ & $62(63.9 \%)$ & \multirow{2}{*}{$0.001^{\star *}$} \\
\hline & More than 10 years & $0(0.0 \%)$ & $35(43.2 \%)$ & $35(36.1 \%)$ & \\
\hline \multirow{2}{*}{ Smoking } & Yes & $12(75.0 \%)$ & $59(72.8 \%)$ & $71(73.2 \%)$ & \multirow{2}{*}{$0,999^{* *}$} \\
\hline & No & $4(25.5 \%)$ & $22(27.2 \%)$ & $26(26.8 \%)$ & \\
\hline \multirow{3}{*}{$\begin{array}{c}\text { Systemic } \\
\text { Arterial } \\
\text { Hypertension }\end{array}$} & Absence & $3(18.8 \%)$ & $2(2.5 \%)$ & $5(5.2 \%)$ & \multirow{3}{*}{$0.047^{\star}$} \\
\hline & Controlled & $6(37.5 \%)$ & $30(37.0 \%)$ & $36(37.1 \%)$ & \\
\hline & Uncontrolled & $7(43.8 \%)$ & $49(60.5 \%)$ & $56(57.7 \%)$ & \\
\hline
\end{tabular}

${ }^{\star}$ Chi-square test; ${ }^{* *}$ Fisher's exact test; ${ }^{* * *}$ Fisher-Freeman-Halton.

Table 5. Difference between the means of the control variables and the diabetic retinopathy screening score (DRSS).

\begin{tabular}{cccc}
\hline \multirow{2}{*}{ Quantitative variables } & \multicolumn{2}{c}{ DRSS } & \multirow{2}{*}{ p-value } \\
\cline { 2 - 3 } Age & Medium risk & High risk & $0.507^{\star}$ \\
BMI & $64.1 \pm 10.3$ & $66.1 \pm 10.7$ & $\leq 0.001^{\star *}$ \\
Systolic blood pressure & $25.9 \pm 2.2$ & $29.9 \pm 4.3$ & $0.636^{\star *}$ \\
Diastolic blood pressure & $151.8 \pm 23.0$ & $152.5 \pm 20.1$ & $0.522^{\star *}$ \\
Hemoglycotest & $83.6 \pm 24.6$ & $89.3 \pm 12.5$ & $0.057^{\star *}$ \\
WC/height ratio & $145.1 \pm 46.9$ & $189.4 \pm 79.9$ & $0.001^{\star}$ \\
Visual Acuity RE & $0.59 \pm 0.38$ & $0.64 \pm 0.55$ & $0.480^{\star *}$ \\
Visual Acuity LE & $0.31 \pm 0.58$ & $0.33 \pm 0.52$ & $0.091^{\star *}$
\end{tabular}

* Student t test; ${ }^{* *}$ Mann-Whitney test. 


\section{Discussion}

Chronic non-communicable diseases (NCDs) became the main causes of death in the world, killing more people each year than all other combined causes [20]. In Brazil, in the year 2017, NCDs were responsible for about $57 \%$ of deaths, in the age group of 30 to 69 years, being considered one of the biggest public health problems today [18]. In this context, there is Diabetes Mellitus, considered an epidemic in the 21st century [6] and Diabetics Retinopathy, the most common complication of DM and one of the main causes of visual impairment among adults working in the developed world [16] [21] [22] [23] [24] [25].

Regarding screening for DM and DR, seeking early treatment, it is necessary to know the epidemiological characteristics of these patients in populations [16], since their surveillance is of great importance for the structuring of health programs and policies focused on disease promotion and prevention [14] [15] [16] [17] [18].

Based on the MRRF-IDRS, it is observed that there are several risk factors and markers for the onset and progression of DR, although the residual risk remains, requiring specific attention from general practitioner and ophthalmologist [26] Therefore, the DRSS has variables such as: age, abdominal obesity, BMI, physical activity, history of diabetes (controlled or not), time of diabetes and smoking. In addition to the score parameters, the history of systemic arterial hypertension requires monitoring; however, in reality it is not done in the northwestern region of Brazil. Thus, requiring scientific investigation as it was performed in these humanitarian missions.

Among the main clinical findings, it was observed that the participants were predominantly female (64.9\%). In those with DR, 8 (66.7\%) were women and 4 (33.3\%) men. Despite the high prevalence of females, such data showed no significant association with the risk of developing DR $(\mathrm{p}=0.727)$. In Saudi Arabia, women also had a higher prevalence of DR compared to men [27]. In a Brazilian study [16], 63.6\% were female, although the data regarding gender was not significantly associated with visual impairment in the study. In the USA, males were independently associated with the presence of DR (Odds ratio [OR], 2.07; 95\% CI, 1.39 - 3.10) [28]. In general, the findings in relation to gender are controversial. Probably, this higher frequency of women in the current study can be explained by the fact that men are not interested in answering the call for the screening in question, because they do not want to and/or because they have (SUS) more work activities in the field [29]. Moreover, the occurrence of widowhood is higher among women, as their life expectancy is significantly higher than men [29], particularly in cities in the countryside, especially in northeastern Brazil.

The mean age was of recruited patients was greater than 65 years in the present investigation, a result higher than that found in the Brazilian study carried out in Pernambuco [17], whose mean age was $58.4 \pm 12.0$ years. As in another Brazilian study [16], the mean age was $51.8 \pm 13.6$ years. However, in a 
study conducted in Spain, the mean age was similar [30]. Such data demonstrate that the citizens of the city of São Mamede-Paraíba do not regularly seek the National Health System (SUS), leaving it to do in later age, when symptoms are already advanced.

A higher prevalence of smokers was also found among the diabetics examined (73.2\%). However, such data showed no significant association with the risk of developing DR ( $\mathrm{p}=0.999$ ). In the literature, in most studies, smoking does not appear to be associated with DR [31] [32], but for public health, the importance of smoking cessation should still be recommended [32].

BMI values were high $\left(29.3 \pm 4.3 \mathrm{~kg} / \mathrm{m}^{2}\right)$ and the waist circumference/height ratio (WC/height) was equal to or greater than 0.6 , in addition, the waist circumference variable showed a significant association $(\mathrm{p}<0.001)$ with the risk of developing diabetic retinopathy. Comparing these data with those of the ophthalmological examination, it was found that BMI and $\mathrm{WC} /$ height ratio with higher values present a high risk of developing DR. The other variables showed no difference between the DRSS risk groups. A study carried out in the city of Santander (Spain) [30] also points to BMI as an independent risk factor for DR. Another Chinese population-based study [33] found that patients with DR had a high BMI ( $\mathrm{p}<0.0001)$.

It is well known that BMI has been used as a diagnostic measure for obesity for many years [34] and, considering that there is a significant relationship between obesity and diabetes risk, it was natural to consider the potential effect of obesity on the incidence of DR, which became evident especially in non-proliferative DR [35]. Therefore, it shows agreement with the data found in the present study.

The use of the WC/height ratio to detect abdominal obesity and the health risks associated with it was first proposed in the mid-90s and, currently, it is observed that the WC/height ratio was a better predictor and better marker discriminatory power than the waist circumference measure for diabetes, dyslipidemia, risk of hypertension and cardiovascular diseases in both genders in populations of various nationalities and ethnic groups. Therefore, values above 0.5 indicate a high risk of developing cardiovascular or metabolic disease [34]. In the current study, it is also observed that the WC/height ratio proved to be an important risk factor for DR development; evidence that has not been observed in other studies.

It was also observed that the variables time of diabetes and systemic arterial hypertension showed a significant association ( $\mathrm{p}<0.001)$ with the risk of developing DR, as demonstrated in the study by the American Diabetes Association [36] which reveals that the prevalence of DR increased with duration of diabetes, HbA1c levels and blood pressure. A study carried out in the city of Santander (Spain) [30] also points out systemic arterial hypertension as an independent risk factor for DR. In China [37], higher HbA1c (OR, 1.111; 95\% CI 1.078 to 1.154 ) and higher systolic blood pressure (OR, 1.014; 95\% CI 1.009 to 1.018 ) was also associated with the presence of DR. Another Chinese study [33] revealed that patients with DR had more hypertension $(\mathrm{p}=0.002)$ and longer duration of 
diabetes ( $\mathrm{p}<0.0001)$. In a case-control study with African Americans [38] with type 2 diabetes, the duration of diabetes, systolic blood pressure and insulin use were strong risk factors for the development of proliferative diabetic retinopathy. In the present study, blood glucose levels did not differ between risk groups for DRSS ( $\mathrm{p}=0.057$ ), however, as blood glucose data was obtained using Hemoglycotest, such findings should be interpreted with caution.

In this study, the variable physical activity also showed a significant association ( $\mathrm{p}<0.001$ ) with the risk of developing DR, in which $37.1 \%$ of the participants considered themselves sedentary and $48.5 \%$ practiced light physical activities. A similar study carried out in Indonesia [39], showed that a longer duration of daily sedentary lifestyle ( $>3$ hours) was significantly associated with the presence of DR (OR 1.66; 95\% CI $1.17-2.35 ; \mathrm{p}<0.01$ ) and DR threatening vision (OR 1.74; 1.16 - 2.62; $\mathrm{p}<0.01$ ). In fact, supervised physical training has been shown to improve glycemic control and insulin sensitivity [40] [41] [42]. These data reinforce the idea that diabetic people continue to practice inappropriate habits such as eating a diet rich in carbohydrates and processed foods, physical inactivity, obesity, among others. Therefore, it is necessary studies that sensitize this population to the worsening of health and quality of life if such habits persist.

According to the result of the DRSS, it was found that the majority of interviewed patients (85.6\%) had a high risk of developing DR. However, the prevalence of DR found was below that expected.

One of the main ophthalmological findings found in the exam was vascular changes compatible with Hypertensive Retinopathy (HR) grade I/II in $72.1 \%$ of the cases, with a right eye $(1.0 \%)$ and a left eye $(1.0 \%)$ with signs of venous occlusion. These data reflect the fact that $94.8 \%$ of the patients examined had systemic arterial hypertension (SAH) associated with DM2. In the group with DR, 83.3\% had SAH. This reveals that the clinical control of basic diseases is not being performed satisfactorily in the city of the study. A similar study, carried out in Portugal [43], showed that among the diabetic patients examined, $73 \%$ of them had SAH, and the group with retinopathy had a significantly higher prevalence of hypertensive patients (79.6\% versus $66.4 \%)$. In a study carried out in Sub-Saharan Africa [28], it was observed that three eyes had occlusion of the central retinal artery and one eye occlusion of the central retinal vein, all in patients with DM2, but did not report data related to HR. In a Brazilian study [16], a greater proportion of patients with hypertension had DR, but it was not statistically significant. These data make clear, once again, the importance of NCDs in the world, representing a great challenge to health professionals in the third millennium [44]. Therefore, arterial hypertension, in addition to causing physical changes in blood vessels, can also exacerbate the threatening effects of vision in DR [45], increasing the risk of the appearance and progression of RD [31].

Another ophthalmological finding of major impact was the presence of cataracts in about $50 \%$ of the eyes of the examined patients, among those with DR, $8 / 12$ patients $(66.7 \%)$ were diagnosed with cataracts. In a similar Brazilian study 
[16], the rate of $35.7 \%$ was found for those patients with DR and cataracts. In sub-Saharan Africa [28], in those with DM2, clinically significant cataracts were present in both eyes in $12 \%$ of individuals and in one eye in $3 \%$. These data reinforce the idea that cataracts are considered the leading cause of blindness worldwide and the second leading cause of visual impairment after refractive error. Its prevalence generally exceeds $50 \%$ in developing countries. In addition, it is known that DM2 is associated with approximately twice the risk of cataracts compared to the general population [46]. Therefore, it shows an association with the data found in the study.

The DR prevalence in the present study was $12.4 \%, 10.3 \%$ of which were compatible with non-proliferative diabetic retinopathy (RDNP) and $2.1 \%$ with proliferative diabetic retinopathy (RDP). In a national study [16], conducted in the São Paulo State countryside, it was observed that the prevalence of DR was 7.62\% (95\% CI 5.02\% - 10.20\%) of participants with self-reported type 2 diabetes. In another Brazilian study [17], this one in the state of Pernambuco, it was observed that $39.4 \%$ of type 2 diabetic patients living in the state countryside presented alterations compatible with DR. In a study comparing the causes of blindness certifications in England and Wales [11], the prevalence of $\mathrm{DR} /$ maculopathy was $14.4 \%$. In another study in northern Spain [30], the prevalence of DR was $8.56 \%$ (CI: $5.81 \%-11.32 \%$ ). The prevalence of DR in Saudi Arabia was $36.1 \%$ [47], while the prevalence in the USA is $28.5 \%$ [48]. These data demonstrate the profound discrepancy and non-homogenization of national data, as well as international data, regarding theme in question. This is probably due to differences in study methodologies, population characteristics and the determination and classification of DR. It also reflects the possible underreporting of diabetic patients registered at SUS in the city of São Mamede-Paraíba. Another possible cause for this lower prevalence may be due to used diagnostic methods.

It is important to note that of the 12 patients diagnosed with DR in this study, only one patient (8.3\%) actually knew about his diagnosis. In addition, $50 \%$ of patients diagnosed with DR had visual impairment on visual acuity test (low vision or blindness- $\log$ Mar 0.6 or worse), a rate higher than that found in another Brazilian study [43], in which $38.7 \%$ of individuals with DR had low vision or were blind. In the USA, the prevalence of DR with vision risk was $4.4 \%$ (95\% CI, $3.5 \%$ - 5.7\%) [48], whereas in England, the prevalence of visual impairment was $3.4 \%$, being $0.39 \%$ with severe visual impairment [27]. In sub-Saharan Africa, $8.5 \%$ were visually impaired and $3.6 \%$ had severe visual impairment or blindness [28]. This fact reinforces the need for screening and greater awareness of diabetes and DR in Brazil, especially in rural cities with a lack of resources for specialized services; reinforcing the idea that in this country the level of information of the diabetic patients in relation to the possibility of developing retinopathy and blindness is still unsatisfactory.

One of the strengths of the study lies in the fact that the evaluations were car- 
ried out with a random representative sample, using a standardized protocol and trained staff. It is also important to comment that, until now, none of the studies on the topic developed here in Brazil [16] [17] have produced a diabetic retinopathy screening score, making this an original study.

Among the limitations, it was observed that about 150 diabetics are registered at SUS in the city of São Mamede-PB. Taking into account that the prevalence of diabetes in the west state of São Paulo is 8.6\% [16], about 660 type 2 diabetic patients should be registered. Thus, the number of diabetics registered at SUS in São Mamede does not necessarily represent the prevalence based on evidence of this condition, as many residents do not seek SUS on a regular basis.

Another limitation of this study was the lack of data on laboratory measurements such as serum glucose and glycosylated hemoglobin, cholesterol, renal function assessment, among others, which could be influencing the results found.

Another limitation is the fact that the screening was done through indirect ophthalmoscopy, a method with $82 \%$ sensitivity and $95 \%$ specificity. Screening studies performed with fund us photographs may show greater sensitivity and specificity for detecting this complication, especially in the initial cases [19] [49] [50] [51] [52] [53]. However, in studies with a high volume of exams and limited budget, where the population is examined in your place of residence, indirect ophthalmoscopy is often used and can be considered an acceptable method of examination.

\section{Conclusions}

The main ophthalmological findings were vascular alterations compatible with hypertensive retinopathy grade $\mathrm{I} / \mathrm{II}$ in $72.1 \%$ of the cases and cataracts in about $50 \%$ of the eyes. The prevalence of DR in the present study was $12.4 \%$ and only one patient actually knew about his diagnosis. In addition, $50 \%$ of patients with DR had visual impairment. These data reinforce the idea that in Brazil, the level of information of the diabetic population in relation to the possibility of developing retinopathy and blindness is still unsatisfactory, in addition, the humanitarian action that generated the study was important in order to expand the screening for DR and other morbidities for other municipalities in the region and, eventually, for other states in Brazil.

When applying the score and comparing its data with the findings of the eye exam, it was observed that the variables waist circumference, physical activity, time of diabetes and arterial hypertension showed a significant association $(\mathrm{p}<0.001)$ with the risk of developing DR, as well as the variables $\mathrm{BMI}$ and $\mathrm{WC} /$ height ratio with higher values presented a high risk of developing DR.

It was concluded that there was an association between medium and high risk diabetics of DRSS with ophthalmological changes, recommending that all people with these characteristics be referred to the specialist, in order to screen for DR and other conditions caused by diabetes. The use of the score can therefore reduce possible flaws in the prevention and strict control of diabetic retinopathy, thereby preventing its progression and improving the health of patients and avoiding 
high treatment costs.

\section{Conflicts of Interest}

The authors declare no conflicts of interest regarding the publication of this paper.

\section{References}

[1] Sun, H.Y., Cheng, Y.H., Yan, Z.P., Liu, X.K. and Zhang, J. (2020) Mining the Proliferative Diabetic Retinopathy-Associated Genes and Pathways by Integrated Bioinformatic Analysis. International Ophthalmology, 40, 269-279. https://doi.org/10.1007/s10792-019-01158-w

[2] Guariguata, L., Whiting, D.R., Hambleton, I., Beagley, J., Linnenkamp, U. and Shaw, J.E. (2014) Global Estimates of Diabetes Prevalence for 2013 and Projections for 2035. Diabetes Research and Clinical Practice, 103, 137-149. https://doi.org/10.1016/j.diabres.2013.11.002

[3] DeFronzo, R.A. (2004) Pathogenesis of Type 2 Diabetes Mellitus. Medical Clinics of North America, 88, 787-835. https://doi.org/10.1016/j.mcna.2004.04.013

[4] Tao, Y.W., Gu, Y.L., Mao, X.Q., Zhang, L. and Pei, Y.F. (2020) Effects of Probiotics on Type II Diabetes Mellitus: A Meta-Analysis. Journal of Translational Medicine, 18, Article No. 30. https://doi.org/10.1186/s12967-020-02213-2

[5] Kalogeropoulos, D., Kalogeropoulos, C., Stefaniotou, M. and Neofytou, M. (2020) The Role of Tele-Ophthalmology in Diabetic Retinopathy Screening. Journal of Optometry, 13, 262-268.

[6] Caruso, R., Magon, A., Baroni, I., et al. (2018) Health Literacy in Type 2 Diabetes Patients: A Systematic Review of Systematic Reviews. Acta Diabetologica, 55, 1-12. https://doi.org/10.1007/s00592-017-1071-1

[7] Gilon, P. (2020) The Role of $\alpha$-Cells in Islet Function and Glucose Homeostasis in Health and Type 2 Diabetes. Journal of Molecular Biology, 432, 1367-1394. https://doi.org/10.1016/j.jmb.2020.01.004

[8] Scanlon, P.H. (2017) Screening Intervals for Diabetic Retinopathy and Implications for Care. Current Diabetes Reports, 17, 96. https://doi.org/10.1007/s11892-017-0928-6

[9] Mozetic, V., Daou, J., Martimbianco, A.L. and Riera, R. (2017) What Do Cochrane Systematic Reviews Say about Diabetic Retinopathy? Sao Paulo Medical Journal, 135, 79-87. https://doi.org/10.1590/1516-3180.2016.0356040117

[10] Cheung, N., Mitchell, P. and Wong, T.Y. (2010) Diabetic Retinopathy. The Lancet, 376, 124-136. https://doi.org/10.1016/S0140-6736(09)62124-3

[11] Flaxman, S., Bourne, R.R.A., Resnikoff, S., Ackland, P., Braithwaite, T., Cicinelli, M.V., Das, A., Jonas, J.B., Keeffe, J., Kempen, J.H., Leasher, J., Limburg, H., Naidoo, K., Pesudovs, K., Silvester, A., Stevens, G.A., Tahhan, N., Wong, T.Y. and Taylor, H.R. (2017) Global Causes of Blindness and Distance Vision Impairment 1990-2020: A Systematic Review and Meta-Analysis. The Lancet Global Health, 5, e1221-e1234.

[12] Williams, R., et al. (2004) Epidemiology of Diabetic Retinopathy and Macular Edema: A Systematic Review. Eye (London), 18, 963-983. https://doi.org/10.1038/sj.eye.6701476

[13] Ruta, L.M., et al. (2013) Prevalence of Diabetic Retinopathy in Type 2 Diabetes in Developing and Developed Countries. Diabetes Medications, 30, 387-398. 
https://doi.org/10.1111/dme.12119

[14] Younis, N., et al. (2003) Incidence of Sight-Threatening Retinopathy in Patient with Type 2 Diabetes in the Liverpool Diabetic Eye Study: A Cohort Study. The Lancet, 361, 195-200. https://doi.org/10.1016/S0140-6736(03)12267-2

[15] Bourne, R.R., Stevens, G.A., White, R.A., Smith, J.L., Flaxman, S.R. and Price, H. (2013) Causes of Vision Loss Worldwide, 1990-2010: A Systematic Analysis. The Lancet Global Health, 1, e339-e349. https://doi.org/10.1016/S2214-109X(13)70113-X

[16] Schellini, S.A., Carvalho, G.M., Rendeiro, F.S., Padovani, C.R. and Hirai, F.E. (2014) Prevalence of Diabetes and Diabetic Retinopathy in a Brazilian Population. Ophthalmic Epidemiology, 21, 33-38. https://doi.org/10.3109/09286586.2013.868004

[17] Escarião, P.H.G., Arantes, T.E.F., Figueiroa, F.N.C., Urtiga, R.D., Florêncio, T.L.T. and Arcoverde, A.L.A.L. (2008) Epidemiologia e diferenças regionais da retinopatia diabética em Pernambuco, Brasil. Arquivos Brasileiros de Oftalmologia, 71, 172-175. https://doi.org/10.1590/S0004-27492008000200008

[18] Secretaria de Vigilância em Saúde (2019) Boletim Epidemiológico: Panorama da vigilância de doenças crônicas não transmissíveis no Brasil, 2018. Ministério da Saúde. v50, n40.

https://www.saude.gov.br/images/pdf/2020/janeiro/16/Boletim-epidemiologico-SVS -40-v2.pdf

[19] Younis, N., Broadbent, D.M., Vora, J.P. and Harding, S.P. (2003) Liverpool Diabetic Eye Study. Incidence of Sight-Threatening Retinopathy in Patients with Type 2 Diabetes in the Liverpool Diabetic Eye Study: A Cohort Study. The Lancet, 361, 195-200. https://doi.org/10.1016/S0140-6736(03)12267-2

[20] Kaushal, K., Mahajan, A., Parashar, A., Dhadwal, D.S., Jaswal, V.M.S., Jaret, P. and Mazta, S.R. (2017) Validity of Madras Diabetes Research Foundation: Indian Diabetes Risk Score for Screening of Diabetes Mellitus among Adult Population of Urban Field Practice Area, Indira Gandhi Medical College, Shimla, Himachal Pradesh, India. Indian Journal of Endocrinology and Metabolism, 21, 876-881. https://doi.org/10.4103/ijem.IJEM 361 16

[21] Acharjee, S., Ghosh, B., Al-Dhubiab, B.E. and Nair, A.B. (2013) Understanding Type 1 Diabetes: Etiology and Models. Canadian Journal of Diabetes, 37, 269-276. https://doi.org/10.1016/j.jcjd.2013.05.001

[22] Al-Mutairi, H.F., Mohsen, A.M. and Al-Mazidi, Z.M. (2007) Genetics of Type I Diabetes. Kuwait Medical Journal, 39, 107e15.

[23] Pociot, F. and McDermott, M.F. (2002) Genetics of Type 1 Diabetes Mellitus. Genes \& Immunity, 3, 235e49. https://doi.org/10.1038/sj.gene.6363875

[24] Op de Beeck, A. and Eizirik, D.L. (2016) Viral Infections in Type 1 Diabetes Mellitus-Why the $\beta$ Cells? Nature Reviews Endocrinology, 12, 263-273.

https://doi.org/10.1038/nrendo.2016.30

[25] Principi, N., Berioli, M.G., Bianchini, S. and Esposito, S. (2017) Type 1 Diabetes and Viral Infections: What Is the Relationship? Journal of Clinical Virology, 96, 26-31. https://doi.org/10.1016/j.jcv.2017.09.003

[26] Jenkins, A.J., Joglekar, M.V., Hardikar, A.U., Keech, A.C., N’Neal, D. and Januszewski, A.S. (2015) Biomarkers in Diabetic Retinopathy. The Review of Diabetic Studies, 12, 159-195. https://doi.org/10.1900/RDS.2015.12.159

[27] Sivaprasad, S., Gupta, B., Gulliford, M.C., et al. (2012) Ethnic Variation in the Prevalence of Visual Impairment in People Attending Diabetic Retinopathy Screening 
in the United Kingdom (DRIVE UK). PLoS ONE, 7, e39608. https://doi.org/10.1371/journal.pone.0039608

[28] Glover, S.J., Burgess, F.I., Cohen, D.B., Harding, S.P., Hofland, H.W.C., Zijlstra, E. and Allain, T.J. (2012) Prevalence of Diabetic Retinopathy, Cataract and Visual Impairment in Patients with Diabetes in Sub-Saharan Africa. British Journal of Ophthalmology, 96, 156-161. https://doi.org/10.1136/bjo.2010.196071

[29] Silva, S.P.C. and Menandro, M.C.S. (2014) As representações sociais da saúde e de seus cuidados para homens e mulheres idosos. Saúde e Sociedade, 23, 626-640. https://doi.org/10.1590/S0104-12902014000200022

[30] Castillo-Otí, J.M., Cañal-Villanueva, J., García-Unzueta, M.T., Galván-Manso, A.I., Callejas-Herrero, M.R. and Muñoz-Cacho, P. (2020) Prevalencia y factores de riesgo asociados a la retinopatía diabética en Santander. Norte de España [Prevalence and Risk Factors Associated with Diabetic Retinopathy in Santander. Northern Spain]. Atención Primaria, 52, 29-37. https://doi.org/10.1016/j.aprim.2018.10.001

[31] Boelter, M.C., Azevedo, M.J., Gross, J.L. and Lavinsky, J. (2003) Risk Factors for Diabetic Retinopathy. Arquivos Brasileiros de Oftalmologia, 66, 239-247. https://doi.org/10.1590/S0004-27492003000200024

[32] Cai, X., Chen, Y., Yang, W., Gao, X., Han, X. and Ji, L. (2018) The Association of Smoking and Risk of Diabetic Retinopathy in Patients with Type 1 and Type 2 Diabetes: A Meta-Analysis. Endocrine, 62, 299-306. https://doi.org/10.1007/s12020-018-1697-y

[33] Yin, L., Zhang, D., Ren, Q., Su, X. and Sun, Z. (2020) Prevalence and Risk Factors of Diabetic Retinopathy in Diabetic Patients: A Community Based Cross-Sectional Study. Medicine (Baltimore), 99, e19236. https://doi.org/10.1097/MD.0000000000019236

[34] Ashwell, M., Gunn, P. and Gibson, S. (2012) Waist-to-Height Ratio Is a Better Screening Tool than Waist Circumference and BMI for Adult Cardiometabolic Risk Factors: Systematic Review and Meta-Analysis. Obesity Reviews, 13, 275-286. https://doi.org/10.1111/j.1467-789X.2011.00952.x

[35] Zhu, W., Wu, Y., Meng, Y.-F., Xing, Q., Tao, J.-J. and Lu, J. (2018) Association of Obesity and Risk of Diabetic Retinopathy in Diabetes Patients: A Meta-Analysis of Prospective Cohort Studies. Medicine (Baltimore), 97, e11807. https://doi.org/10.1097/MD.0000000000011807

[36] Yau, J.W., Rogers, S., Kawasaki, R., et al. (2012) Global Prevalence and Major Risk Factors of Diabetic Retinopathy. Diabetes Care, 35, 556-564. https://doi.org/10.2337/dc11-1909

[37] Zhang, G., Chen, H., Chen, W. and Zhang, M. (2017) Prevalence and Risk Factors for Diabetic Retinopathy in China: A Multi-Hospital-Based Cross-Sectional Study. British Journal of Ophthalmology, 101, 1591-1595. https://doi.org/10.1136/bjophthalmol-2017-310316

[38] Penman, A., Hancock, H., Papavasileiou, E., James, M., Idowu, O., Riche, D.M., Fernandez, M., Brauner, S., Smith, S.O., Hoadley, S., Richardson, C., Vazquez, V., Chi, C., Andreoli, C., Husain, D., Chen, C.J. and Sobrin, L. (2016) Risk Factors for Proliferative Diabetic Retinopathy in African Americans with Type 2 Diabetes. Ophthalmic Epidemiology, 23, 88-93. https://doi.org/10.3109/09286586.2015.1119287

[39] Dharmastuti, D.P., Agni, A.N., Widyaputri, F., Pawiroranu, S., Sofro, Z.M., Wardhana, F.S., Haryanto, S., Widayanti, T.W., Kotha, S., Gupta, P. and Sasongko, M.B. (2018) Associations of Physical Activity and Sedentary Behaviour with Vision- 
Threatening Diabetic Retinopathy in Indonesian Population with Type 2 Diabetes Mellitus: Jogjakarta Eye Diabetic Study in the Community (JOGED.COM). Ophthalmic Epidemiology, 25, 113-119. https://doi.org/10.1080/09286586.2017.1367410

[40] Melmer, A., Kempf, P. and Laimer, M. (2018) The Role of Physical Exercise in Obesity and Diabetes. Praxis (Bern 1994), 107, 971-976.

https://doi.org/10.1024/1661-8157/a003065

[41] Mascena, G.V., Cavalcante, M.S.B., Marcelino, G.B., Holanda, S.A. and Brandt, C.T. (2012) Cardiovascular Risk Factors in Students from the Health Sciences Center-Campina Grande-Brazil. Medicina (Ribeirão Preto), 45, 322-328. https://doi.org/10.11606/issn.2176-7262.v45i3p322-328

[42] Umpierre, D., Ribeiro, P.A., Kramer, C.K., et al. (2011) Physical Activity Advice Only or Structured Exercise Training and Association with HbA1c Levels in Type 2 Diabetes: A Systematic Review and Meta-Analysis. JAMA, 305, 1790-1799. https://doi.org/10.1001/jama.2011.576

[43] Nabais, C., Pereira, J., Pereira, P., Capote, R., Morbeck, S. and Raposo, J. (2011) Diabetic Retinopathy and Associated Conditions, What Relationship? A Study in Portuguese Patients with Type 2 Diabetes. Acta Médica Portuguesa, 24, 71-78.

[44] Santos, J.C. and Moreira, T.M.M. (2012) Fatores de risco e complicações em hipertensos diabéticos de uma regional sanitária do nordeste brasileiro. Revista da Escola de Enfermagem da USP, 46, 1125-1132. https://doi.org/10.1590/S0080-62342012000500013

[45] Fraser-Bell, S., Symes, R. and Vaze, A. (2017) Hypertensive Eye Disease: A Review. Clinical \& Experimental Ophthalmology, 45, 45-53. https://doi.org/10.1111/ceo.12905

[46] Drinkwater, J.J., Davis, W.A. and Davis, T.M.E. (2019) A Systematic Review of Risk Factors for Cataract in Type 2 Diabetes. Diabetes/Metabolism Research and Reviews, 35, e3073. https://doi.org/10.1002/dmrr.3073

[47] El-Bab, M.F., Shawky, N., Al-Sisi, A. and Akhtar, M. (2012) Retinopathy and Risk Factors in Diabetic Patients from Al-Madinah Al-Munawarah in the Kingdom of Saudi Arabia. Clinical Ophthalmology, 6, 269-276. https://doi.org/10.2147/OPTH.S27363

[48] Zhang, X., Saaddine, J.B., Chou, C.F., et al. (2010) Prevalence of Diabetic Retinopathy in the United States, 2005-2008. JAMA, 304, 649-656. https://doi.org/10.1001/jama.2010.1111

[49] Taylor-Phillips, S., Mistry, H., Leslie, R., et al. (2016) Extending the Diabetic Retinopathy Screening Interval beyond 1 Year: Systematic Review. British Journal of Ophthalmology, 100, 105-114. https://doi.org/10.1136/bjophthalmol-2014-305938

[50] Tung, T.H., Shih, H.C., Chen, S.J., et al. (2008) Economic Evaluation of Screening for Diabetic Retinopathy among Chinese Type 2 Diabetics: A Community-Based Study in Kinmen, Taiwan. Journal of Epidemiology, 18, 225-233.

https://doi.org/10.2188/jea.JE2007439

[51] Scanlon, P.H., Malhotra, R., Greenwood, R.H., et al. (2003) Comparison of Two Reference Standards in Validating Two Field Mydriatic Digital Photography as a Method of Screening for Diabetic Retinopathy. British Journal of Ophthalmology, 87, 1258-1263. https://doi.org/10.1136/bjo.87.10.1258

[52] Olson, J.A., Strachan, F.M., Hipwell, J.H., et al. (2003) A Comparative Evaluation of Digital Imaging, Retinal Photography and Optometrist Examination in Screening for Diabetic Retinopathy. Diabetic Medicine, 20, 528-534. 
https://doi.org/10.1046/j.1464-5491.2003.00969.x

[53] Flores, R., Donoso, R. and Anguita, R. (2019) Management of Diabetic Retinopathy Using Telemedicine and Network Integration. Revista Medica de Chile, 147, 444-450. https://doi.org/10.4067/S0034-98872019000400444 